\title{
Imaging data in COVID-19 patients: focused on echocardiographic findings
}

\author{
Roya Sattarzadeh Badkoubeh ${ }^{1} \cdot$ Meysam Khoshavi ${ }^{1} \cdot$ Vahideh Laleh far $^{1} \cdot$ Ali Mehrakizadeh $^{1} \cdot$ Masoud Eslami $^{1}$. \\ Faeze Salahshour ${ }^{2} \cdot$ Akram Sardari $^{1} \cdot$ Saeed Safari $^{3} \cdot$ Farnoosh Larti $^{1}{ }^{10} \cdot$ Steven Nissen $^{4}$
}

Received: 20 October 2020 / Accepted: 23 December 2020 / Published online: 16 January 2021

(c) The Author(s), under exclusive licence to Springer Nature B.V. part of Springer Nature 2021

\begin{abstract}
To assess imaging data in COVID-19 patients and its association with clinical course and survival and 86 consecutive patients (52 males, 34 females, mean age $=58.8$ year) with documented COVID-19 infection were included. Seventy-eight patients $(91 \%)$ were in severe stage of the disease. All patients underwent transthoracic echocardiography. Mean LVEF was $48.1 \%$ and mean estimated systolic pulmonary artery pressure (sPAP) was $27.9 \mathrm{mmHg}$. LV diastolic dysfunction was mildly abnormal in 49 patients (57.6\%) and moderately abnormal in 7 cases (8.2\%). Pericardial effusion was present in 5/86 (minimal in size in 3 cases and mild- moderate in 2). In $32 / 86$ cases (37.2\%), the severity of infection progressed from "severe" to "critical". Eleven patients (12.8\%) died. sPAP and computed tomography score were associated with disease progression (P value $=0.002,0.002$ respectively). Tricuspid annular plane systolic excursion (TAPSE) was significantly higher in patients with no disease progression compared with those who deteriorated $(\mathrm{P}$ value $=0.005$ ). Pericardial effusion (minimal, mild or moderate) was detected more often in progressive disease $(\mathrm{P}=0.03)$. sPAP was significantly lower among survivors $(\mathrm{P}$ value $=0.007$ ). Echocardiographic findings (including systolic PAP, TAPSE and pericardial effusion), total CT score may have prognostic and therapeutic implication in COVID-19 patients.
\end{abstract}

Keywords COVID-19 $\cdot$ Echocardiography $\cdot$ Systolic PAP $\cdot$ Pericardial effusion $\cdot$ Chest CT $\cdot$ Total CT score

\section{Introduction}

Outbreak of the newly emerged Coronavirus (SARS-CoV-2, COVID-19 disease) in late 2019 has been reported to involve multiple organ systems, including the cardiovascular system. Initial reports from Wuhan, China in December 2019

Roya Sattarzadeh Badkoubeh and Meysam Khoshavi had similar contribution in the study process

Farnoosh Larti

farnooshlarti@gmail.com

1 Cardiology Department, Imam Khomeini Hospital Complex, Tehran University of Medical Sciences, End of Keshavarz Boulevard, 1419733141 Tehran, Iran

2 Radiology Department, Imam Khomeini Hospital Complex, Tehran University of Medical Sciences, Tehran, Iran

3 General Surgery Department, Firouzgar General Hospital, Iran University of Medical Sciences, Tehran, Iran

4 Cardiovascular Medicine Department, Cleveland Clinic, Cleveland, USA documented the presence of cardiac injury. Several hypotheses were suggested for the mechanism of cardiac injury [1-3] and echocardiography has been advocated for management of cardiac complications [4].

We conducted the current study to evaluate the potential role of echocardiography in detecting both significant and subtle structural or functional abnormalities in patients with documented COVID-19 infection and predicting patients' outcome based on echocardiographic findings.

\section{Methods}

The study was performed in a high-volume COVID-19 referral center in Tehran, Iran. From March 5th 2020 to March 27th 2020, we studied 86 consecutive COVID-19 positive with echocardiography. COVID-19 infection was confirmed by real-time reverse transcription polymerase chain reaction (rRT-PCR) from nasopharyngeal swabs. The study proposal was approved by the hospital ethical research committee. 
Figure 1 shows the process of patient enrollment and their outcomes.

To describe the clinical picture of the patients, we classified them into 3 groups according to a published study from Wuhan, China-common, severe or critical [5]. The "common" group had fever, respiratory tract symptoms or evidence of pneumonia on imaging; the "severe" group had any of the followings: respiratory distress, resting respiratory rate $\geq 30 / \mathrm{min}$, finger $\mathrm{O}_{2}$ saturation $\leq 93 \%$; and in the "critical" group, one of these conditions must have been present: intubation required for respiratory failure, the presence of shock or intensive care unit (ICU) admission due to multi-organ system failure. We defined shock as signs and symptoms of organ hypoperfusion in a patient with adequate preload status. Patient management and transfer to either general ward or ICU were guided by the hospital COVID-19 protocol which was based on the national practice guidelines

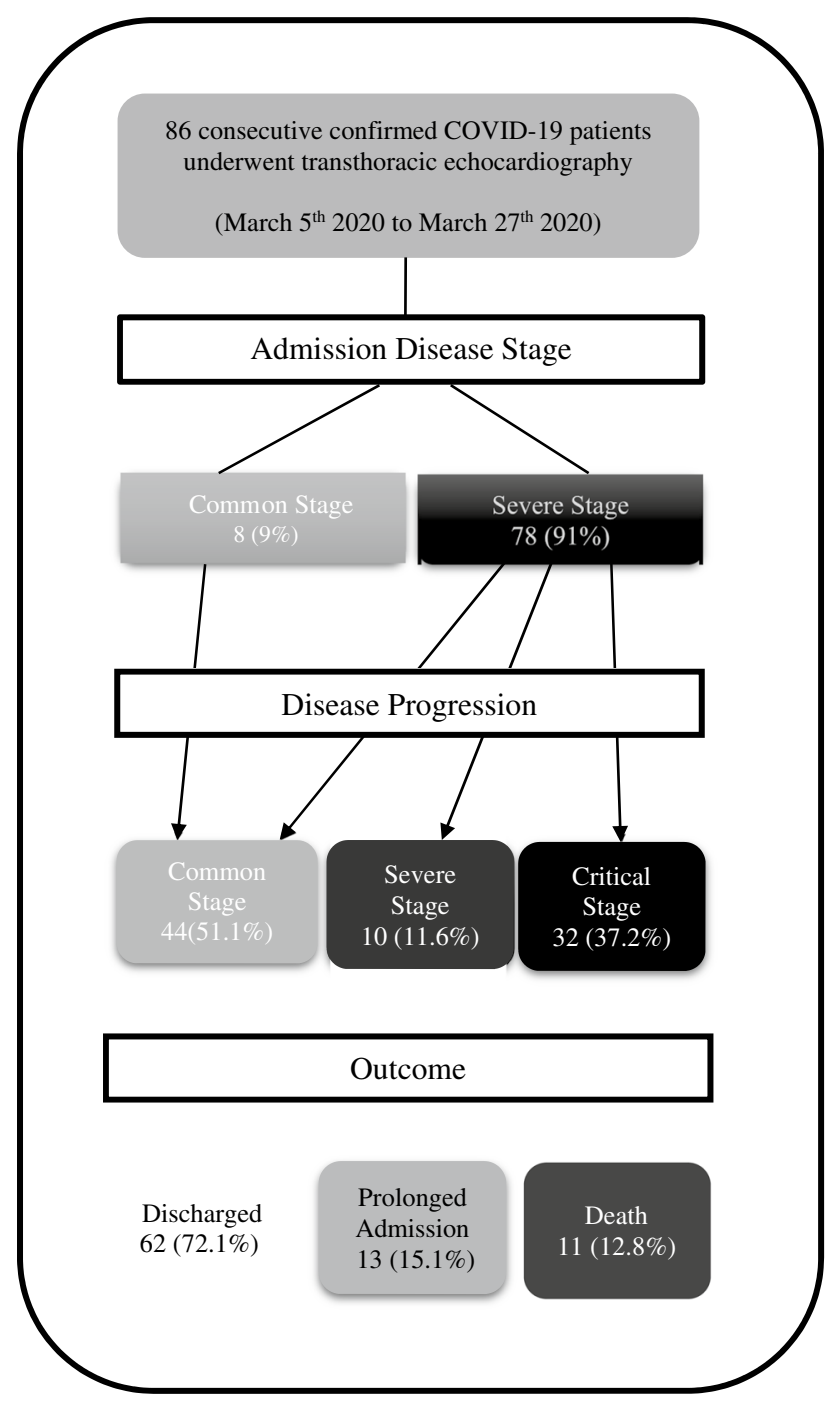

Fig. 1 The process of patient enrolment and outcomes for SARS-CoV-2 management [6]. Radiologic assessment for hospitalized COVID-19 patients included chest X-ray and chest CT. A semiquantitative scoring system for expression of pulmonary involvement was used $[7,8]$ to score parenchymal involvement of each of 5 lung lobes (total CT score ranged from 0 to 25 for each patient).

The demographic, clinical, echocardiographic and chest CT data of patients were collected. All bedside echocardiography studies were performed within the first 3 days of admission by two cardiologists who were responsible for the management of COVID-19 patients. Echocardiographic examination was performed with GE Vivid S5 ultrasound machine using standard personal protection equipment (PPE) for operator safety and only essential echocardiographic data was collected including size and function of both ventricles, presence of pericardial effusion, significant valvular heart disease, LV diastolic dysfunction and estimated systolic pulmonary artery pressure (sPAP). In Fig. 2, sample echocardiographic data that were measured and analyzed are shown. To analyze data, we classified the severity of LV systolic dysfunction into severe (LVEF $\leq 30 \%)$, moderate ( $\mathrm{LVEF}=31-44 \%$ ) and mild dysfunction or normal $(\mathrm{LVEF} \geq 45 \%)$.

Statistical analyses were performed using Statistical Product and Service Solutions (SPSS) version 26.0 (IBM Corp, Armonk, NY). Descriptive variables were presented as frequencies and percentages and continuous variables were described as mean (SD) values. Non-parametric variables were analyzed with Mann-Whitney $\mathrm{U}$ test. $\mathrm{P}$ value $\leq 0.05$ was considered significant.

\section{Results}

In the current study, 86 consecutive COVID-19 patients were included (Fig. 1). Among these, 52 (60.5\%) were male and $34(39.5 \%)$ were female with mean age of 58.8 years (range 16-86 years). The patients presented to the emergency department with dyspnea in $69(80.2 \%)$, fever in $45(52.3 \%)$, cough in $26(30.2 \%)$, myalgia in $19(22.1 \%)$ and chest pain in $4(4.7 \%)$ cases. The presenting clinical picture was "severe" in $78(91 \%)$ and "common" in $8(9 \%)$ patients. No patient in this study classified as "critical" stage at presentation. The two most common comorbidities were hypertension in 36 (41.9\%) and diabetes in 29 (33.7\%). Demographic, clinical presentation and comorbidities of the study population are presented in Table 1.

Results of bedside echocardiography are shown in Table 2. Mean estimated LVEF was $48.1 \%(\mathrm{SD}=8.4 \%)$ and mean sPAP was $27.9 \mathrm{mmHg}(\mathrm{SD}=6.1)$. $\mathrm{LVEF}$ was $\geq 45 \%$ in 71 patients $(82.6 \%)$, moderately reduced $(\mathrm{LVEF}=31-44 \%)$ in 10 cases $(11.6 \%)$ and severe ( $\mathrm{LVEF} \leq 30 \%)$ in 5 patients (5.8\%). Based on American Society of Echocardiography 
Fig. 2 Sample echocardiographic views and data that were obtained and measured in the study population including parasternal long axis view (a), short axis views (b and $\mathbf{c}$ ), apical four chamber view (d), assessment of LV diastolic function (e and $\mathbf{f}$ ) and RV systolic function by TAPSE (g). TAPSE Tricuspid Annular Systolic Plane Excursion
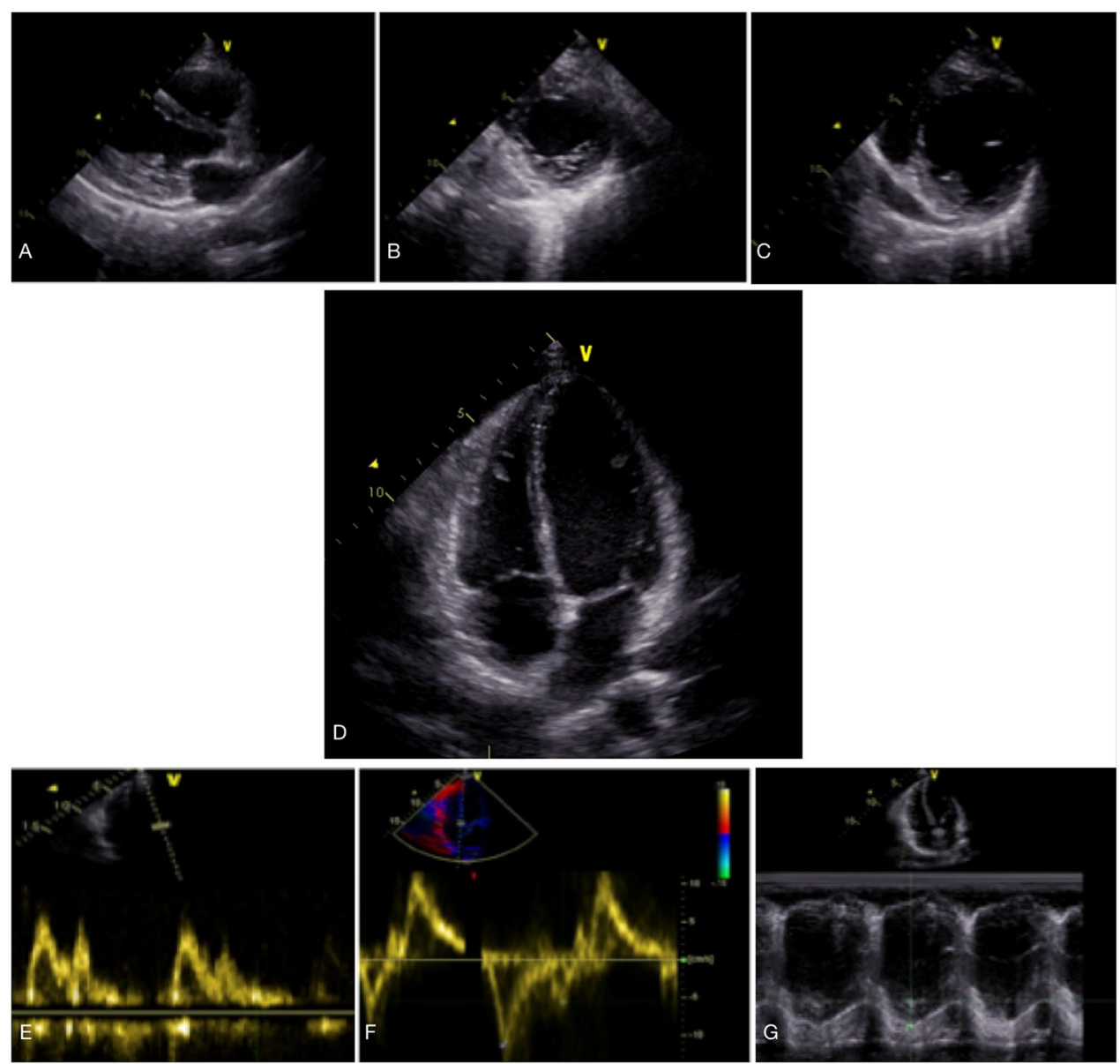

(ASE) guidelines [9], LV diastolic function was reported as follows: normal in 29 (34.1\%), grade $1 \mathrm{LV}$ diastolic dysfunction in $49(57.6 \%)$ and grade $2 \mathrm{LV}$ diastolic dysfunction in $7(8.2 \%)$ patients. Data for LV diastolic function was not available in one case.

RV systolic function was reported as follows: normal in $70(81.4 \%)$, mild or moderate RV systolic dysfunction in 14 (16.3\%) and severe dysfunction in 2 patients (2.3\%). Significant valvular abnormalities included severe aortic stenosis (AS) in $2(2.3 \%)$, moderate to severe AS combined with aortic regurgitation in $2(2.3 \%)$, moderate mitral regurgitation (MR) in 11 and severe MR in $1(14.3 \%)$, moderate mitral stenosis in $1(1.2 \%)$, moderate pulmonic insufficiency in 2 (2.4\%) and moderate tricuspid regurgitation in 11 (13.1\%) cases. Pericardial effusion was not a common finding, minimal to mild in $4(4.7 \%)$ cases and moderate in only one patient $(1.2 \%)$. Pulmonary hypertension was present only in seven cases $(8.1 \%)$ and the maximum SPAP in our study was $50 \mathrm{mmHg}$.

DICOM files of chest CT scans were available in 50 patients. In the remaining patients, chest CT scan had been performed in a referring center with no DICOM files available to review. Chest $\mathrm{CT}$ findings had ground-glass opacification in 27 (54\%) and consolidation in $23(46 \%)$. Chest involvement was bilateral in $46(92 \%)$ patients. Mean total CT score was $7.46(\mathrm{SD}=3.4)$ (Table 2).

Clinical deterioration to the next stage occurred in 32 patients (37\% of all cases) from severe to critical (Fig. 1). No patient in common stage progressed to a worse stage. No association was found between disease progression, LVEF and LV systolic dysfunction categories however total CT score was significantly higher in the group with the disease progression compared to the stable patients (9.06 vs $6.39, \mathrm{P}=0.002$ ). Disease progression had a trend to occur more frequently in patients with LV diastolic dysfunction compared with patients with normal LV diastolic function $(\mathrm{P}$ value $=0.052)$. Mean tricuspid annular plane systolic excursion (TAPSE) was higher in patients with no disease progression compared with those who deteriorated during their hospital course (mean TAPSE, $22.17 \mathrm{~mm}$ vs $19.53 \mathrm{~mm}, \mathrm{P}$ value $=0.005$ ). Systolic PAP was significantly higher in patients with disease progression compared with clinically stable patients (mean sPAP, $34.0 \mathrm{mmHg}$ vs $26.2 \mathrm{mmHg}, \mathrm{P}=0.002$ ). Lastly, pericardial effusion was detected significantly more frequently 
Table 1 Demographic, clinical presentation and comorbidities of study population

\begin{tabular}{|c|c|}
\hline Baseline characteristics & Number (percent) \\
\hline Mean age & 58.8 years ( $16-86$ years) \\
\hline Female age & $58.25 \pm 19.36$ years \\
\hline Male age & $64.79 \pm 17.69$ years \\
\hline Female & $34(39.5 \%)$ \\
\hline Male & $52(60.5 \%)$ \\
\hline \multicolumn{2}{|l|}{ Clinical presentation } \\
\hline Dyspnea & $69(80.2 \%)$ \\
\hline Fever & $45(52.3 \%)$ \\
\hline Cough & $26(30.2 \%)$ \\
\hline Myalgia & $19(22.1 \%)$ \\
\hline Chest pain & $4(4.7 \%)$ \\
\hline \multicolumn{2}{|c|}{ Disease stage at presentation } \\
\hline Common & $8(9.3 \%)$ \\
\hline Severe & $78(90.7 \%)$ \\
\hline \multicolumn{2}{|l|}{ Comorbidities } \\
\hline Hypertension & $36(41.9 \%)$ \\
\hline Diabetes & $29(33.7 \%)$ \\
\hline \multirow[t]{3}{*}{ Coronary artery disease } & CABG $8(9.3 \%)$ \\
\hline & PCI $7(8.1 \%)$ \\
\hline & $\begin{array}{l}\text { Medical treatment } \\
6(7.0 \%)\end{array}$ \\
\hline Hyperlipidemia & $9(10.5 \%)$ \\
\hline CKD & $8(9.3 \%)$ \\
\hline Cancer & $5(5.8 \%)$ \\
\hline CVA & $3(3.5 \%)$ \\
\hline Cigarette smoking & $3(3.5 \%)$ \\
\hline COPD & $3(3.5 \%)$ \\
\hline Heart failure & $1(1.2 \%)$ \\
\hline
\end{tabular}

$C K D$ chronic kidney disease, $C O P D$ chronic obstructive pulmonary disease, $C V A$ cerebrovascular accident, $P C I$ percutaneous coronary intervention

in initial echocardiography of patients who deteriorated during their hospital course $(\mathrm{P}$ value $=0.034)$ (Table 3$)$.

The observed outcome was: 62 discharged cases (72.1\%), 11 deaths $(12.8 \%)$, and 13 patients with prolonged (more than 14 days) hospital stay (15.1\%). Average length of stay in 73 patients with definite outcome (discharge or death) was 8.7 days.

Analyzing data from the mortality group (Table 4) showed that mean sPAP was significantly higher in the patients who died (mean sPAP, $32.78 \mathrm{mmHg}$ vs $27.32 \mathrm{mmHg}$, $\mathrm{P}$ value $=0.007$ ). Moreover, mortality had a trend to occur more frequently in patients with LV diastolic dysfunction compared with patients with normal LV diastolic function $(\mathrm{P}$ value $=0.055)$. The mortality group was not different from the surviving group in terms of total CT score. Although significant left sided valvular heart disease was not
Table 2 Bedside echocardiographic and chest CT data

\begin{tabular}{ll}
\hline Echocardiographic data $(\mathrm{n}=86)$ & \\
\hline LV systolic dysfunction & \\
LVEF (\%), mean \pm SD & $48.16 \pm 8.46$ \\
Normal and mild LV systolic dysfunction & $71(82.6 \%)$ \\
Moderate LV systolic dysfunction & $10(11.6 \%)$ \\
Severe LV systolic dysfunction & $5(5.8 \%)$ \\
LV diastolic function & \\
Normal & $29(34.1 \%)$ \\
Grade 1 LV diastolic dysfunction & $49(57.6 \%)$ \\
Grade 2 LV diastolic dysfunction & $7(8.2 \%)$ \\
sPAP (mmHg), mean \pm SD & $27.96 \pm 6.13$ \\
Pericardial effusion & \\
None & $81(94.2 \%)$ \\
Minimal & $3(3.5 \%)$ \\
Mild & $1(1.2 \%)$ \\
Moderate & $1(1.2 \%)$ \\
Chest CT findings (n=50) & \\
Total CT score, mean \pm SD & $7.46 \pm 3.40$ \\
Distribution & \\
Left sided & $2(4 \%)$ \\
Right sided & $2(4 \%)$ \\
Bilateral & $46(92 \%)$ \\
Pattern & \\
GGO & $27(54.0 \%)$ \\
Consolidation & $23(46.0 \%)$ \\
Result & \\
Intermediate & $44(88 \%)$ \\
Highly suggestive & \\
\hline
\end{tabular}

$G G O$ ground glass opacification, $L V E F$ left ventricular ejection fraction, $S P A P$ systolic pulmonary artery pressure

common in this study population, both cases with severe AS did not survive. SPAP was higher in patients with significant valvular heart disease (moderate or greater severity). Despite higher SPAP in patients with valvular heart disease, disease progression, mortality and CT score showed no significant difference in patients with and without significant valvular heart disease $(\mathrm{P}$ value $=0.44,0.46,0.87)$ respectively.

Gender was a discriminating factor in some aspects. Compared to men, women were younger (54.2 years vs 61.9 years, $P$ value $=0.030)$, had higher mean LVEF $(50.1 \%$ vs $46.8 \%, P$ value $=0.045)$ and less LV diastolic dysfunction $(\mathrm{P}$ value $=0.036)$. Despite these differences, our analysis shows that gender has no effect either on mortality or disease progression. Total CT score had moderate correlation with hospital stay $(\mathrm{P}$ value $=0.003, \mathrm{r}=0.4)$. 
Table 3 Complete comparison of clinical and imaging data in patients with and without disease progression

\begin{tabular}{|c|c|c|c|}
\hline Baseline characteristics $(n=86)$ & $\begin{array}{l}\text { No progression } \\
(\mathrm{n}=54)\end{array}$ & $\begin{array}{l}\text { Progression } \\
(\mathrm{n}=32)\end{array}$ & $P$ value \\
\hline Age (years), mean $\pm \mathrm{SD}$ & $54.46 \pm 17.33$ & $55.40 \pm 22.54$ & 0.306 \\
\hline Sex (male) & $30(57.7 \%)$ & $22(42.3 \%)$ & 0.163 \\
\hline \multicolumn{4}{|l|}{ Comorbidities } \\
\hline Diabetes & $22(75.9 \%)$ & $7(24.1 \%)$ & 0.059 \\
\hline COPD & $1(33.3 \%)$ & $2(66.7 \%)$ & 0.285 \\
\hline Smoking & $4(80 \%)$ & $1(20 \%)$ & 0.404 \\
\hline Hyperlipidemia & $8(88.9 \%)$ & $1(11.1 \%)$ & 0.084 \\
\hline CVA & $2(66.7 \%)$ & $1(33.3 \%)$ & 0.888 \\
\hline Cancer & $1(20 \%)$ & $4(80 \%)$ & 0.062 \\
\hline Coronary artery disease & $13(61.9 \%)$ & $8(38.1 \%)$ & 0.560 \\
\hline Heart failure & $1(100 \%)$ & $0(0 \%)$ & 0.441 \\
\hline CKD & $4(50 \%)$ & $4(50 \%)$ & 0.337 \\
\hline Hypertension & $20(55.6 \%)$ & $16(44.4 \%)$ & 0.171 \\
\hline Echocardiographic data $(\mathrm{n}=86)$ & $\begin{array}{l}\text { No progression } \\
(\mathrm{n}=54)\end{array}$ & Progression $(n=32)$ & $P$ value \\
\hline $\operatorname{LVEF}(\%)$, mean \pm SD & $52.31 \pm 1.11$ & $45.50 \pm 5.26$ & 0.160 \\
\hline Normal/Mild LV systolic dysfunction & $42(59.2 \%)$ & $29(40.8 \%)$ & \\
\hline Moderate LV systolic dysfunction & $8(80 \%)$ & $2(20 \%)$ & \\
\hline Severe LV systolic dysfunction & $4(80 \%)$ & $1(20 \%)$ & \\
\hline LV diastolic dysfunction & $31(55.4 \%)$ & $25(44.6 \%)$ & 0.052 \\
\hline $\mathrm{sPAP}(\mathrm{mmHg})$, mean $\pm \mathrm{SD}$ & $26.23 \pm 3.91$ & $34.00 \pm 8.21$ & 0.002 \\
\hline \multicolumn{4}{|l|}{ Pericardial effusion } \\
\hline None & $53(65.4 \%)$ & $28(34.6 \%)$ & 0.034 \\
\hline Minimal & $1(33.3 \%)$ & $2(66.7 \%)$ & \\
\hline Mild & $0(0 \%)$ & $1(100 \%)$ & \\
\hline Moderate & $0(0 \%)$ & $1(100 \%)$ & \\
\hline TAPSE & $22.17 \pm 3.81$ & $19.53 \pm 3.90$ & 0.005 \\
\hline Chest CT findings $(n=50)$ & No progression $(\mathrm{n}=30)$ & Progression $(n=20)$ & $P$ value \\
\hline Total CT score & $9.06 \pm 3.73$ & $6.39 \pm 2.72$ & 0.002 \\
\hline Distribution & & & 0.791 \\
\hline Left sided & $1(50 \%)$ & $1(50 \%)$ & \\
\hline Right sided & $2(100 \%)$ & $0(0 \%)$ & \\
\hline Bilateral & $27(58.7 \%)$ & $19(41.3 \%)$ & \\
\hline \multicolumn{4}{|l|}{ Pattern } \\
\hline GGO & $16(59.3 \%)$ & $11(40.7 \%)$ & 0.569 \\
\hline Consolidation & $14(60.9 \%)$ & $9(39.1 \%)$ & \\
\hline \multicolumn{4}{|l|}{ Result } \\
\hline Intermediate & $3(50 \%)$ & $3(50 \%)$ & 0.598 \\
\hline Highly suggestive & $27(61.4 \%)$ & $17(38.6 \%)$ & \\
\hline
\end{tabular}

$C K D$ chronic kidney disease, $C O P D$ chronic obstructive pulmonary disease, $C V A$ cerebrovascular accident, $G G O$ ground glass opacification, $L V E F$ left ventricular ejection fraction, $S P A P$ systolic pulmonary artery pressure, TAPSE tricuspid annular systolic plane excursion

\section{Discussion}

Clarifying the pattern of organ involvement and disease progression course is one of the main foci of ongoing clinical research about COVID-19. Although there are multiple reports on cardiovascular involvement in COVID-19 disease, limited data are available in determination of prognosis with early echocardiography in Corona virus infection. We conducted this single center study to evaluate initial imaging data including echocardiographic features of COVID-19 
Table 4 Complete comparison of clinical and imaging data in mortality and survivors' group

\begin{tabular}{|c|c|c|c|}
\hline Baseline characteristics $(n=86)$ & Survivors $(\mathrm{n}=75)$ & Death $(n=11)$ & $\mathrm{P}$ value \\
\hline Age (years), mean \pm SD & $58.89 \pm 15.33$ & $58.82 \pm 19.92$ & 0.948 \\
\hline Sex (male) & $47(90.4 \%)$ & $5(9.6 \%)$ & 0.20 \\
\hline \multicolumn{4}{|l|}{ Comorbidities } \\
\hline Diabetes & $27(93.1 \%)$ & $2(6.9 \%)$ & 0.208 \\
\hline COPD & $3(100 \%)$ & $0(0 \%)$ & 0.66 \\
\hline Smoking & $4(100 \%)$ & $0(0 \%)$ & 0.556 \\
\hline Hyperlipidemia & $9(100 \%)$ & $0(0 \%)$ & 0.273 \\
\hline CVA & $3(100 \%)$ & $0(0 \%)$ & 0.66 \\
\hline Cancer & $4(80 \%)$ & $1(20 \%)$ & 0.504 \\
\hline Coronary artery disease & $20(95.2 \%)$ & $1(4.8 \%)$ & 0.190 \\
\hline Heart failure & $1(100 \%)$ & $0(0 \%)$ & 0.872 \\
\hline CKD & $6(75 \%)$ & $2(25 \%)$ & 0.271 \\
\hline Hypertension & $32(88.9 \%)$ & $4(11.1 \%)$ & 0.478 \\
\hline Echocardiographic data $(\mathrm{n}=86)$ & Survivors $(\mathrm{n}=75)$ & Death $(n=11)$ & $P$ value \\
\hline $\operatorname{LVEF}(\%)$, mean $\pm \mathrm{SD}$ & $47.79 \pm 8.88$ & $50.68 \pm 4.04$ & 0.517 \\
\hline Normal/Mild LV systolic dysfunction & $60(84.5 \%)$ & $11(15.5 \%)$ & 0.522 \\
\hline Moderate LV systolic dysfunction & $10(100 \%)$ & $0(0 \%)$ & \\
\hline Severe LV systolic dysfunction & $5(100 \%)$ & $0(0 \%)$ & \\
\hline LV diastolic dysfunction & $46(82.1 \%)$ & $10(17.9 \%)$ & 0.055 \\
\hline $\mathrm{sPAP}(\mathrm{mmHg})$, mean $\pm \mathrm{SD}$ & $27.32 \pm 5.88$ & $32.78 \pm 6.18$ & 0.007 \\
\hline \multicolumn{4}{|l|}{ Pericardial effusion } \\
\hline None & $71(87.7 \%)$ & $10(12.3 \%)$ & 0.274 \\
\hline Minimal & $3(100 \%)$ & $0(0 \%)$ & \\
\hline Mild & $0(0 \%)$ & $1(100 \%)$ & \\
\hline Moderate & $1(100 \%)$ & $0(0 \%)$ & \\
\hline TAPSE & $21.4 \pm 4.07$ & $19.8 \pm 3.61$ & 0.258 \\
\hline Chest CT findings $(\mathrm{n}=50)$ & Survivors $(n=43)$ & Death $(n=7)$ & $\mathrm{P}$ value \\
\hline Total CT score & $7.31 \pm 3.20$ & $8.57 \pm 4.80$ & 0.361 \\
\hline \multicolumn{4}{|l|}{ Distribution } \\
\hline Left sided & $2(100 \%)$ & $0(0 \%)$ & 0.536 \\
\hline Right sided & $2(100 \%)$ & $0(0 \%)$ & \\
\hline Bilateral & $39(84.8 \%)$ & $7(15.2 \%)$ & \\
\hline \multicolumn{4}{|l|}{ Pattern } \\
\hline GGO & $23(85.2 \%)$ & $4(14.8 \%)$ & 0.593 \\
\hline Consolidation & $20(87 \%)$ & $3(13 \%)$ & \\
\hline \multicolumn{4}{|l|}{ Result } \\
\hline Intermediate & $5(83.3 \%)$ & $1(16.7 \%)$ & 0.616 \\
\hline Highly suggestive & $38(86.4 \%)$ & $6(13.6 \%)$ & \\
\hline
\end{tabular}

$C K D$ chronic kidney disease, $C O P D$ chronic obstructive pulmonary disease, $C V A$ cerebrovascular accident, GGO ground glass opacification, $L V E F$ left ventricular ejection fraction, $S P A P$ systolic pulmonary artery pressure, TAPSE tricuspid annular systolic plane excursion

patients and to find any associations between these findings and the clinical course of the disease. Most of the patients (90.7\%) in this study had severe form of COVID-19 disease and $37 \%$ of them experienced clinical deterioration.

Comparing patients who died with survivors, no statistically significant difference between mean LVEF and chest CT involvement were found. Only SPAP was significantly different between survivors and non-survivors. From echocardiographic perspective, sPAP was higher and TAPSE was lower significantly in patients with disease progression. Patients with disease progression also had higher CT score and prevalence of pericardial effusion. Disease progression and mortality was not associated with comorbidities including diabetes, CAD and significant valvular 
heart diseases. After Logistic Regression and adjustment of comorbidities, the association between SPAP and disease progression/mortality remained significant. When CT score was added to the regression model, association between sPAP and disease progression became non-significant, implying that sPAP was not an independent predictor of disease progression. In other words, probably higher $\mathrm{CT}$ scores resulted in higher sPAP in these patients. We did not find an association between CT score and mortality in our study. This may be due to the number of patients $(15.1 \%)$ with prolonged hospitalization (undetermined outcome) at the time of data analysis. These findings underscore the importance of pulmonary artery pressure and right ventricular function in the course of the COVID-19 disease. An observational study by Hani M MahmoudElsayed was done to evaluate echocardiographic features of COVID-19 patients and its association with cardiac biomarkers. The two common echocardiographic abnormalities were RV dilatation and RV dysfunction while LV systolic function was normal in most of their patients [10]. Another retrospective study by William E. Moody showed RV systolic dysfunction is an independent predictor of all-cause mortality in COVID-19 infection [11]. One significant difference of our study with these two researches is the fact that in nearly fifty percent of their study participants, TR velocity and subsequently sPAP could not be measured by echocardiography. In a study by Szekely Y, systematic echocardiographic evaluation of one hundred COVID-19 positive patients showed LV systolic dysfunction is not a frequent finding (less than 10\%) but RV dilation with or without RV systolic dysfunction is the dominant echocardiographic manifestation [12]. In a review by John F. Park multiple mechanism postulated to play role in the right ventricular dysfunction in these patients including increased after load due to acute respiratory distress syndrome and pulmonary embolism, cardio depressant effect of cytokines and direct viral injury to the right ventricle [13].

In the presenting study, LV diastolic dysfunction had a trend with mortality and disease progression in COVID19 patients but considering great concerns about higher prevalence of heart failure preserved EF (HFpEF) in patients with coronavirus infection [14], this issue needs to be clarified in future studies with larger sample size.

Echocardiographic data in stable COVID-19 patients is not helpful in many mildly ill patients, but in critically ill patients in ICU, attention should be directed to RV systolic function and differential diagnosis of pulmonary hypertension (e.g. pulmonary thromboembolism).

These imaging data have potential importance in clinical practice. Although performing routine echocardiography for COVID-19 patients is not reasonable due to operator safety, applying these data to clinical practice could include optimizing intra-vascular volume status along with treatment of increased LV end-diastolic pressure (e.g. diuretics) in critically ill patients.

\section{Limitations}

1. This study was performed From March 18th 2020 to March 27th 2020. A defined protocol had not been implemented at that time in our hospital regarding time and interval of cardiac biomarker measurements (including cardiac troponin and NT-proBNP) in COVID-19 patients; Hence cardiac biomarker results were not available for all the study participants specifically in the first 3 days of hospital admission.

2. The aim of this cross-sectional study was to detect any cardiac involvement in COVID-19 patients. Unfortunately, there was no information regarding previous cardiac status such as left and right systolic function in all the patients. Myocardial dysfunction that was detected in this group of patients were not necessarily related to COVID-19 disease and may be due to pre-existing cardiac disease, myocarditis or sepsis.

3. Performing follow-up echocardiography in the course of disease progression may have revealed later evidence of LV systolic dysfunction.

4. Most of the study population consisted of severe cases and generalization of our study results to less severely ill COVID-19 patients are not possible.

5. DICOM files of chest $\mathrm{CT}$ were not available for reporting in 36 patients

\section{Conclusions}

Role of echocardiography in management of COVID-19 patients has not been fully defined. However, estimated systolic PAP, TAPSE measurement and pericardial effusion are parameters that should receive special attention in echocardiography. Other imaging data including total CT score may determine disease outcome.

Funding None.

Availability of data Yes, Availability of materials: Measurements of bedside echocardiographic parameters in each patient were performed online during echocardiography as storing data and analyzing echocardiographic images in an offline mode are not feasible in the ICUs and general COVID-19 wards in our hospital. 


\section{Compliance with ethical standards}

Conflict of interest All authors declare that they have no conflict of interest.

\section{References}

1. Madjid M, Safavi-Naeini P, Solomon SD, Vardeny O (2020) Potential effects of coronaviruses on the cardiovascular system: a review. JAMA Cardiol 5:831-840

2. Bonow RO, Fonarow GC, O'Gara PT, Yancy CW (2020) Association of Coronavirus Disease 2019 (COVID-19) with myocardial injury and mortality. JAMA Cardiol. https://doi.org/10.1001/ jamacardio.2020.1105

3. Zheng YY, Ma YT, Zhang JY, Xie X (2020) COVID-19 and the cardiovascular system. Nat Rev Cardiol 17(5):259-260. https:// doi.org/10.1038/s41569-020-0360-5

4. Cameli M, Pastore MC, Soliman Aboumarie H, Mandoli GE, D'Ascenzi F, Cameli P, Bigio E, Franchi F, Mondillo S, Valente S (2020) Usefulness of echocardiography to detect cardiac involvement in COVID-19 patients. Echocardiography 37(8):1278-1286

5. Jin JM, Bai P, He W, Wu F, Liu XF, Han DM, Liu S, Yang JK (2020) Gender differences in patients with COVID-19: focus on severity and mortality. Front Public Health 29(8):152. https://doi. org/10.3389/fpubh.2020.00152

6. Health imo. (2020) National guideline and flowchart for diagnosis and treatment of novel coronavirus(COVID-19), 6th edn. Iran Ministry of Health, Tehran, $\mathrm{p} 22$

7. Pan F, Ye T, Sun P, Gui S, Liang B, Li L, Zheng D, Wang J, Hesketh RL, Yang L, Zheng C (2020) Time course of lung changes at chest $\mathrm{CT}$ during recovery from coronavirus disease 2019 (COVID-19). Radiology 295(3):715-721. https://doi. org/10.1148/radiol.2020200370
8. Chang YC, Yu CJ, Chang SC, Galvin JR, Liu HM, Hsiao CH, Kuo PH, Chen KY, Franks TJ, Huang KM, Yang PC (2005) Pulmonary sequelae in convalescent patients after severe acute respiratory syndrome: evaluation with thin-section CT. Radiology 236(3):1067-1075. https://doi.org/10.1148/radiol.2363040958

9. Nagueh SF, Smiseth OA, Appleton CP, Byrd BF, Dokainish H, Edvardsen T, Flachskampf FA, Gillebert TC, Klein AL, Lancellotti P, Marino P (2016) Recommendations for the evaluation of left ventricular diastolic function by echocardiography: an update from the American Society of Echocardiography and the European Association of Cardiovascular Imaging. Eur J Echocardiogr 17(12):1321-1360

10. Mahmoud-Elsayed HM, Moody WE, Bradlow WM, Khan-Kheil AM, Senior J, Hudsmith LE, Steeds RP (2020) Echocardiographic findings in patients with COVID-19 pneumonia. Can J Cardiol 36(8):1203-1207

11. Moody WE, Mahmoud-Elsayed HM, Senior J, Gul U, Khan-Kheil AM, Horne S, Banerjee A, Bradlow WM, Huggett R, Hothi SS, Shahid M (2020) Impact of right ventricular dysfunction on mortality in patients hospitalized with COVID-19 according to race. CJC Open

12. Szekely Y, Lichter Y, Taieb P, Banai A, Hochstadt A, Merdler I, Gal Oz A, Rothschild E, Baruch G, Peri Y, Arbel Y, Topilsky Y (2020) Spectrum of cardiac manifestations in COVID-19: a systematic echocardiographic study. Circulation 142(4):342-353. https://doi.org/10.1161/CIRCULATIONAHA.120.047971

13. Park JF, Banerjee S, Umar S (2020) In the eye of the storm: the right ventricle in COVID-19. Pulm Circ. https://doi. org/10.1177/2045894020936660

14. Freaney PM, Shah SJ, Khan SS (2020) COVID-19 and heart failure with preserved ejection fraction. JAMA 324(15):1499-1500

Publisher's Note Springer Nature remains neutral with regard to jurisdictional claims in published maps and institutional affiliations. 